\title{
Synthesis, Isolation and Characterization of three acid and alkaline hydrolytic products of Nimodipine and Development of a valid RP-HPLC method for simultaneous determination of Nimodipine and Citicoline sodium in the presence of Nimodipine degradation products in Bulk and Tablets
}

\author{
Ayman Abo Elmaaty Mohamed iD
}

Faculty of Pharmacy, Port Said University, 23' December St., Port Said, 42526, Egypt

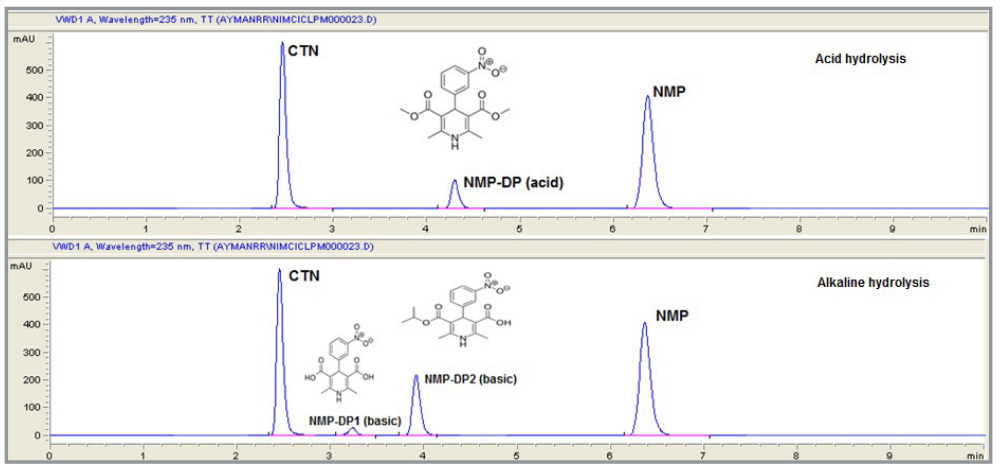

Impurity profiling of active pharmaceutical ingredients is a crucial step in assessing their quality. Moreover, the chemical nature of nimodipine makes it susceptible easily to acidic and alkaline hydrolysis. On the other hand, nimodipine is co-formulated with citicoline sodium pharmaceutically as tablets to treat cerebral ischemia. In this study, three degradation products of nimodipine were synthesized, isolated and characterized with aid of FTIR spectroscopy, ${ }^{1} \mathrm{H}-\mathrm{NMR}$ as well as LC-MS/MS after exposing to drastic acidic and alkaline conditions. Subsequently, a simple, selective and valid RP-HPLC method was developed for simultaneous estimation of nimodipine and citicoline in the presence of nimodipine acid and alkaline degradation products in bulk and tablets. Chromatographic separation was achieved using an isocratic mobile phase consisting of acetonitrile: $0.02 \mathrm{M} \mathrm{KH}_{2} \mathrm{PO}_{4}$ (containing $0.2 \% \mathrm{v} / \mathrm{v}$, triethylamine and adjusted to $\mathrm{pH} 3.0$ with orthophosphoric acid) $(70: 30, \mathrm{v} / \mathrm{v}$ ) at a flow rate $1.0 \mathrm{~mL} \mathrm{~min}{ }^{-1}$ at ambient temperature $\left(25^{\circ} \mathrm{C}\right)$ on a Eurospher II C18 $(250 \mathrm{~mm} \times 4.6 \mathrm{~mm}, 5 \mu \mathrm{m})$ column with UV detection at $270 \mathrm{~nm}$ for citicoline and $235 \mathrm{~nm}$ for nimodipine and its acidic and alkaline hydrolytic products. Linearity, accuracy and precision were found to be acceptable over a concentration range of (4.5-120 $\left.\mathrm{g} \mathrm{m} \mathrm{mL}^{-1}\right)$ for nimodipine and (15-400 $\mathrm{gg} \mathrm{mL}^{-1}$ ) for citicoline. The proposed method could be successfully applied for the routine analysis of the studied drugs in their pharmaceutical preparation in the presence of nimodipine common degradation products without any preliminary separation step.

Cite: Mohamed, A. A. E. Synthesis, Isolation and Characterization of three acid and alkaline hydrolytic products of Nimodipine and Development of a valid RP-HPLC method for simultaneous determination of Nimodipine and Citicoline sodium in the presence of Nimodipine degradation products in Bulk and Tablets. Braz. J. Anal. Chem., 2021, 8 (30), pp 43-58. doi: http://dx.doi. org/10.30744/brjac.2179-3425.AR-52-2020 
Keywords: Nimodipine; Citicoline; Acid and alkaline hydrolysis; Structure elucidation; RP-HPLC.

\section{INTRODUCTION}

Nimodipine (NMP) (Figure 1.a) is 3,5-pyridine dicarboxylic acid, 1,4-dihydro-2,6-dimethyl-4-(3nitrophenyl)-,2-methoxy ethyl 1-methyl ethyl ester [1]. It is a dihydropyridine calcium channel blocker known for its preferential action on cerebral blood vessels and its potential cytoprotective effects by reducing calcium influx into nerve cells [2]. It is the only available therapy with proven benefits for reducing the impact of ischemic neurological deficits after subarachnoid hemorrhage so far [2,3]. Nimodipine can be of some benefits in patients with various forms of dementia [4].

Citicoline sodium (CTN) (Figure 1.b), is Cytidine 5'-(trihydrogendiphosphate) p'-[2- (trimethylammonio) ethyl] ester inner salt [5]. It is cytidine diphosphate-choline, suggested to increase dopamine receptor densities [6] and it helps prevent memory impairment resulting from poor environmental conditions [7]. It is primarily used in pharmacotherapy of brain insufficiency and other related neurological disorders as stroke, brain trauma and Parkinsonism's disease [8].

Nimodipine and citicoline sodium are co-formulated in pharmaceutical preparations as Nimodilat plus $®$ tablets. This combination was found to have an important role in reducing infarct size, and treating cerebral ischemia [9].

Nimodipine USP monograph revealed a conventional titrimetric assay method for Nimodipine determination [1]. Nimodipine was determined in different pharmaceutical formulations using HPLC methods in pharmaceutical dosage forms [10,11] and in plasma [12-14]. Besides, nimodipine was estimated in the presence of its process related impurities [15] and in presence of its acidic, alkaline and photolytic degradation products (no degradation was observed under thermal and oxidative stress conditions) [16]. Moreover, nimodipine (NMP) was determined in human plasma and cerebrospinal fluid of patients with subarachnoid haemorrhage using UHPLC-MS/MS [17].

Citicoline sodium was estimated in bulk and dosage form by HPLC methods [18-20]. Moreover, it was estimated in human plasma [21,22]. Citicoline sodium (CTN) was estimated in combination with piracetam using RP-UPLC [23]. Stress degradation studies were estimated for citicoline sodium (CTN) using RPHPLC [24].

Although, the literature review revealed that stress degradation studies were made on nimodipine (NMP) to indicate its stability under different stress conditions [16]. However, no structure elucidation was reported to any nimodipine (NMP) degradation products. Besides, the literature review revealed that nimodipine (NMP) showed moderate stability under oxidative and high temperature stress conditions [16]. So, in this study the focus was on nimodipine (NMP) acidic and alkaline degradation products preparation, isolation and characterization by LC-MS/MS, ${ }^{1} \mathrm{H}-\mathrm{NMR}$ and FTIR spectroscopy (Figures 1.c, 1.d and 1.e). Obviously, due to a lot of overlapping peaks might appear and bad resolutions attained, conducting a forced degradation study on a combination containing both nimodipine (NMP) and citicoline sodium (CTN) was not the target. To date, the combination of nimodipine (NMP) with citicoline sodium (CTN) was not officially reported in any pharmacopeia and no RP-HPLC method was reported for the rapid estimation of both drugs simultaneously. So, in this study, a RP-HPLC method was developed for the quantitation of nimodipine (NMP) and citicoline sodium (CTN) in combination and in the presence of nimodipine (NMP) acidic and alkaline degradation products. The developed method was validated according to ICH Guidelines [25]. The proposed method is suitable for purity assessment of bulk and dosage forms containing nimodipine alone or in combination of citicoline in reasonable time. 

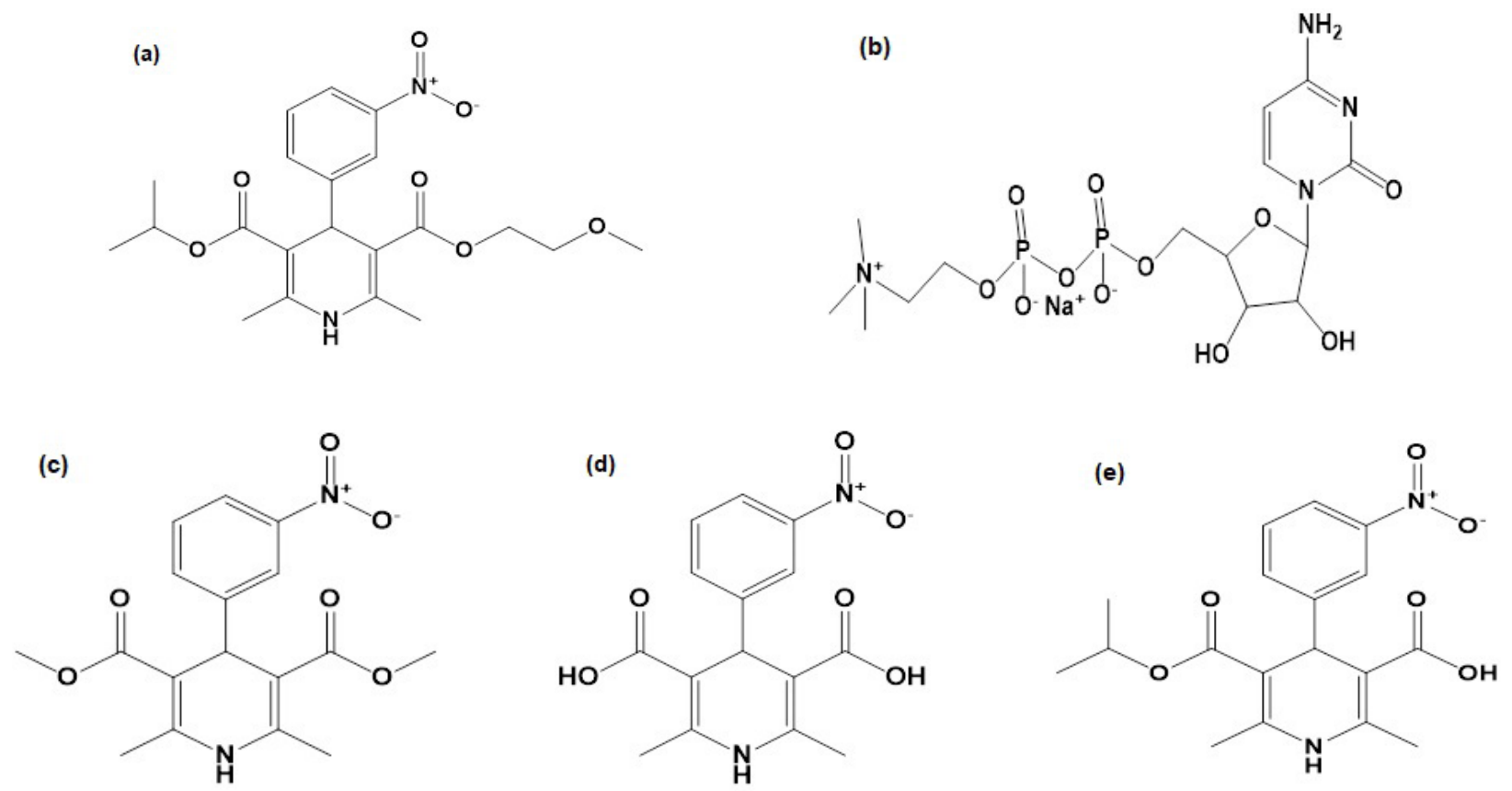

Figure 1. Chemical structures of (a) nimodipine, (b) citicoline sodium, (c) nimodipine acid degradation product (d) nimodipine alkaline degradation product [1] [DP 1], (e) nimodipine alkaline degradation product [2] [DP 2].

\section{MATERIALS AND METHODS Instrumentation}

A chromatographic system consisting of Agilent 1200 series (CA, USA); interface equipped with an Agilent quaternary pump G1311A, Agilent UV-visible detector G1314B, an Agilent manual injector G1328B equipped with $(20 \mu \mathrm{l})$ injector loop, an Agilent degasser G1322A and an Agilent syringe, LC $50 \mu \mathrm{L}$. Separation and quantitation were made on a Eurospher II C18 column (5 $\mu \mathrm{m}, 4.6 \times 250 \mathrm{~mm})$.

Moreover, tandem mass spectrometer - an Agilent triple quadrupole mass spectrometer with an API source (ESI) coupled with an Agilent pump controlled by an Agilent 1200 controller and equipped with an Agilent 1200 autosampler injector was used for analysis. Agilent Mass Hunter software was used for data acquisition.

Furthermore, NMR instrument - a Bruker NMR instrument (USA), $400 \mathrm{MHz}$ and FTIR spectrophotometerShimadzu FTIR spectrophotometer 8400S (Japan), were used.

\section{Materials and Reagents}

Pharmaceutical grade nimodipine (NMP) was supplied and certified by GNP Company $\left(6^{\text {th }}\right.$ October -Egypt) to contain $99.87 \%$. Pharmaceutical grade citicoline sodium (CTN) was supplied and certified by October pharma Company ( $6^{\text {th }}$ October -Egypt) to contain $99.65 \%$. Nimodilat plus ${ }^{\circledR}$ tablets labeled to contain $30 \mathrm{mg}$ nimodipine (NMP) and $100 \mathrm{mg}$ citicoline sodium (CTN) per each tablet, was supplied by Lazar pharmaceutical company (Ecuador). Acetonitrile HPLC grade (Scharlau, Spain) was used. Bidistilled water was produced in-house (Aquatron Water Still, A4000D, U.K). Membrane filters $0.45 \mu \mathrm{m}$ from Teknokroma (Barcelona, Spain) were used. All other chemicals and reagents used were of analytical grade unless indicated otherwise.

\section{Chromatographic Conditions}

Chromatographic separation was achieved on a Eurospher II C18 column $(250 \mathrm{~mm} \times 4.6 \mathrm{~mm}, 5 \mu \mathrm{m})$ by applying isocratic elution based on a mobile phase consisting of acetonitrile:0.02 $\mathrm{M} \mathrm{KH}_{2} \mathrm{PO}_{4}$ (containing 
$0.2 \% \mathrm{v} / \mathrm{v}$, triethylamine and adjusted to $\mathrm{pH} 3.0$ with orthophosphoric acid) $(70: 30, \mathrm{v} / \mathrm{v})$. The mobile phase was pumped through the column at a flow rate of $1 \mathrm{~mL} \mathrm{~min}{ }^{-1}$. Analyses were performed at ambient temperature $\left(25^{\circ} \mathrm{C}\right)$ and detection was programmed to be at $270 \mathrm{~nm}$ from 0-3.49 min for citicoline sodium (CTN) and $235 \mathrm{~nm}$ from 3.5-10 min for nimodipine (NMP) and its acidic and alkaline degradation products. The injection volume was $20 \mu \mathrm{L}$.

Tandem mass spectrometry (LC-MS/MS) was performed using a mobile phase consisting of acetonitrile: $0.1 \%$ formic acid $(80: 20, \mathrm{v} / \mathrm{v})$, delivered at a flow rate of $0.5 \mathrm{~mL} \mathrm{~min}^{-1}$. Separation was performed using an analytical Agilent XDB-C18 column $(50 \times 4.6 \mathrm{~mm})$ with particle size of $1.8 \mu \mathrm{m}$.

\section{Standard solution preparation}

Standard stock solutions of each of nimodipine (NMP) $\left(1 \mathrm{mg} \mathrm{mL}^{-1}\right)$ and citicoline sodium (CTN) (1 mg $\mathrm{mL}^{-1}$ ) were prepared by separately dissolving $100 \mathrm{mg}$ of each drug in $100 \mathrm{~mL}$ mobile phase. The required concentrations were prepared by serial dilutions with mobile phase.

\section{Sample preparation}

\section{Tablet sample preparation}

Twenty tablets were accurately weighed and powdered in a mortar. A quantity of the powdered tablets equivalent to $(100 \mathrm{mg} / 30 \mathrm{mg})$ citicoline sodium (CTN)/ nimodipine (NMP) respectively was sonicated for 15 min with $70 \mathrm{~mL}$ of mobile phase, cooled and transferred quantitatively into a $100 \mathrm{~mL}$ volumetric flask. The solution was completed to volume with mobile phase and filtered to obtain a concentration equivalent to $1000 \mu \mathrm{g} \mathrm{mL}{ }^{-1}$ for citicoline sodium (CTN) and $300 \mu \mathrm{g} \mathrm{mL} \mathrm{L}^{-1}$ for nimodipine (NMP).

\section{Nimodipine acid drastic forced degradation product preparation and isolation}

An amount equivalent to $125 \mathrm{mg}$ of nimodipine (NMP) was dissolved in $250 \mathrm{~mL} 5 \mathrm{M}$ methanolic $\mathrm{HCl}$ (not aqueous $\mathrm{HCl}$, due to poor solubility of nimodipine in water) and transferred quantitatively to a conical flask. Solution was put on reflux at $80^{\circ} \mathrm{C}$ water bath for 6 hours. Flask content was cooled and neutralized to $\mathrm{pH} 7$ using $5 \mathrm{M} \mathrm{NaOH}$. Neutralized solution was evaporated to dryness. Residue formed was dissolved in dichloromethane and put on sonication for $10 \mathrm{~min}$. Filter and evaporate filtrate obtained to dryness in a beaker of known weight and reweight the beaker. Dissolve residue in acetonitrile to get a solution of $500 \mu \mathrm{g}$ $\mathrm{mL}^{-1}$. Methanolic degradation products formed are not real time degradation products, but those forming are only induced degradation conditions.

\section{Nimodipine alkaline drastic forced degradation product preparation and isolation}

An amount equivalent to $100 \mathrm{mg}$ of nimodipine (NMP) was dissolved in $180 \mathrm{~mL}$ dichloromethane in a stoppered conical flask. $20 \mathrm{~mL}$ methanol containing $2.1 \mathrm{mg} \mathrm{NaOH}$ was added to the conical flask (to make $0.25 \mathrm{M} \mathrm{NaOH}$ solution) and flask content was mixed well. Solution was put on reflux at $60^{\circ} \mathrm{C}$ water bath for 2 hours. Flask content was transferred to a beaker and evaporated to dryness. Residue was dissolved in $200 \mathrm{~mL}$ water. Make extraction with $45 \mathrm{~mL}$ dichloromethane three successive times to remove any traces of unreacted ester and alcohol formed. Aqueous layer was separated and neutralized with $0.25 \mathrm{M} \mathrm{HCl}$ to $\mathrm{pH}$ 7. The neutralized aqueous solution was re-evaporated to dryness and cooled. $50 \mathrm{~mL}$ acetonitrile was added and solution sonicated for 10 min then filtered. Filtrate was evaporated in a beaker of known weight and reweight the beaker. Residue was dissolved in acetonitrile to get a solution of $100 \mu \mathrm{gL}^{-1}$.

\section{Procedure}

\section{Linearity and range}

Accurately measured aliquots of standard stock solutions of nimodipine (NMP) and citicoline sodium (CTN) equivalent to $\left(45-1200 \mu \mathrm{g} \mathrm{mL}^{-1}\right)$ and (150-4000 $\left.\mu \mathrm{g} \mathrm{mL}^{-1}\right)$ respectively, were transferred into series of $10 \mathrm{~mL}$ volumetric flasks and completed to volume with mobile phase to get concentration ranges equivalent to $\left(4.5-120 \mu \mathrm{g} \mathrm{mL}^{-1}\right)$ for nimodipine (NMP) and (15-400 $\left.\mathrm{g} \mathrm{mL}^{-1}\right)$ for citicoline sodium (CTN). $20 \mu \mathrm{L}$ aliquot 
of each solution was injected in triplicates onto the chromatograph under the specified chromatographic conditions described in the Chromatographic Conditions item. Calibration curve was constructed by plotting the area under peak (AUP) against the corresponding concentrations (C) of each drug.

Assay of laboratory prepared mixtures and Nimodilat plus ${ }^{\circledR}$ tablet

Laboratory prepared mixtures

The procedures mentioned under the Linearity and Range item were repeated using laboratory prepared mixtures equivalent to $18-110 \mu \mathrm{g} \mathrm{mL}^{-1}$ nimodipine (NMP) (in the presence of 2-30 $\mathrm{gg} \mathrm{mL}^{-1}$ nimodipine (NMP) acidic and alkaline degradation products (10\% to $30 \%$ of nimodipine (NMP), w/w)) and $20-370 \mu \mathrm{g}$ $\mathrm{mL}^{-1}$ citicoline sodium (CTN) (Figures 2 and 3 ).

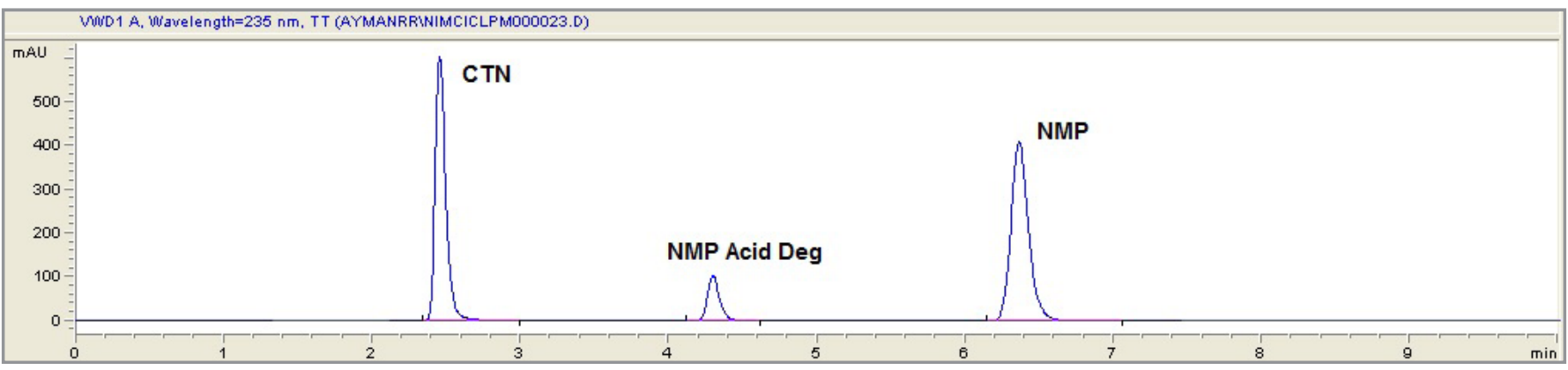

Figure 2. A typical HPLC chromatogram of synthetic ternary mixture of $150 \mu \mathrm{g} \mathrm{mL}^{-1}$ citicoline sodium, $9 \mu \mathrm{mL}^{-1}$ nimodipine acid degradate and $45 \mu \mathrm{g} \mathrm{mL}^{-1}$ nimodipine.

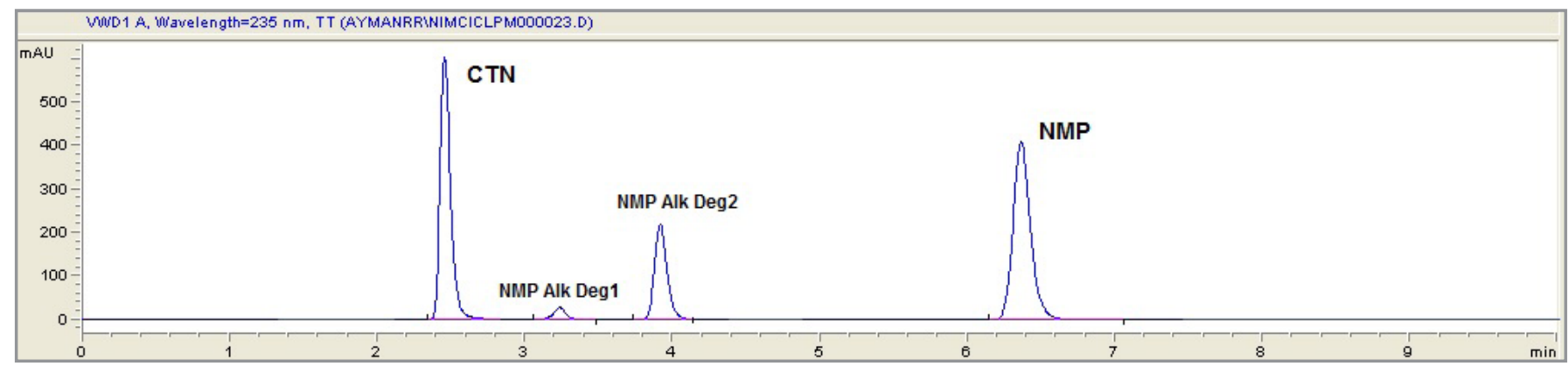

Figure 3. A typical HPLC chromatogram of synthetic ternary mixture of $150 \mu \mathrm{g} \mathrm{mL}^{-1}$ citicoline sodium, $11 \mu \mathrm{g} \mathrm{mL}-1$ nimodipine alkaline degradates and $45 \mu \mathrm{g} \mathrm{mL}^{-1}$ nimodipine

Assay of Nimodilat plus ${ }^{\circledR}$ tablets

Sample solution prepared under the Sample Preparation item was serially diluted with mobile phase to get concentrations equivalent to $9-108 \mu \mathrm{g} \mathrm{mL}-1$ nimodipine (NMP) and 30-360 $\mu \mathrm{g} \mathrm{mL}^{-1}$ citicoline sodium (CTN). Samples were injected in triplicates. Concentrations of nimodipine (NMP) and citicoline sodium (CTN) were calculated using calibration equations.

\section{RESULTS AND DISCUSSION System suitability tests}

System suitability tests are important tests of liquid chromatographic methods in order to reach optimized conditions of the proposed USP method [1]. The parameters of these tests include column efficiency (number of theoretical plates) $(\mathrm{N})$, capacity factor $(\mathrm{K})$, tailing of chromatographic peak $(\mathrm{T})$, resolution $(\mathrm{R})$, and repeatability as \% RSD of peak area for six injections of a solution of a $200 \mu \mathrm{g} \mathrm{mL}^{-1}$ and $60 \mu \mathrm{mL}^{-1}$ for 
citicoline sodium (CTN) and nimodipine (NMP), respectively and reproducibility of retention as \% R.S.D of retention time. The results of these tests for the proposed method were listed in Table I.

Table I. System suitability results of the proposed RP-HPLC method

\begin{tabular}{|c|c|c|c|c|c|c|c|}
\hline \multirow[b]{2}{*}{ Analytical term } & \multicolumn{3}{|c|}{ Acid degradation } & \multicolumn{4}{|c|}{ Alkaline degradation } \\
\hline & CTN & NMP-DP & NMP & CTN & NMP-DP1 & NMP-DP2 & NMP \\
\hline $\begin{array}{l}\text { Number of theoretical } \\
\text { plates }(\mathrm{N})\end{array}$ & 3562 & 14548 & 15172 & 3499 & 7764 & 10699 & 14978 \\
\hline Resolution (R) & 17.99 & \multicolumn{2}{|c|}{11.76} & \multicolumn{2}{|c|}{8.38} & \multicolumn{2}{|c|}{14.2} \\
\hline Capacity factor (K) & 1.502 & 3.352 & 5.379 & 1.497 & 2.231 & 3.042 & 5.382 \\
\hline $\begin{array}{l}\text { Chromatographic peak } \\
\text { tailing }(T)\end{array}$ & 1.348 & 1.205 & 1.201 & 1.321 & 0.965 & 1.239 & 1.187 \\
\hline \multicolumn{8}{|l|}{ RSD $\%$ of 6 injections } \\
\hline Peak area & 0.160 & 0.432 & 0.079 & 0.183 & 0.332 & 0.166 & 0.067 \\
\hline Retention time & 0.184 & 0.272 & 0.071 & 0.166 & 0.226 & 0.097 & 0.082 \\
\hline
\end{tabular}

\section{Validation of analytical method}

\section{Linearity and range}

In this study, six concentrations were chosen for each drug. Each concentration was analyzed three times. Good linearity of the calibration curve was verified by the high correlation coefficient. The analytical data of the calibration curve including standard deviations for the slope and intercept $\left(S_{b}, S_{a}\right)$ were summarized in Table II.

\section{Accuracy}

Accuracy of the results was calculated by \% recovery of laboratory prepared mixtures of 6 different concentrations of citicoline sodium (CTN) and nimodipine (NMP) and also by standard addition technique for Nimodilat plus ${ }^{\circledR}$ tablet. The results obtained including the mean of the recovery and standard deviation were displayed in Table II.

\section{Precision}

The intra-day precision of the method was assessed by six determinations for each of the three concentrations (160, 200, $240 \mu \mathrm{g} \mathrm{mL}-1$ for citicoline sodium (CTN) and 48, 60, $72 \mu \mathrm{g} \mathrm{mL}^{-1}$ for nimodipine (NMP)) representing $80 \%, 100 \%, 120 \%$ for each drug. The repeatability of sample and measurement of peak area for active compound were expressed in terms of percentage relative standard deviation (\%R.S.D.) and found to be less than $1 \%$ in three concentrations. Besides, inter-day precision (using the same three concentrations in triplicates for three consecutive days) was carried out for both drugs and results were displayed in Table II.

\section{Specificity}

Specificity is the ability of the analytical method to measure the analyte response in the presence of interferences. The chromatograms of citicoline sodium (CTN) and nimodipine (NMP) in the sample solutions were found to be identical to the chromatograms obtained by the standard solution. Also, no chromatographic interference from acidic and alkaline degradation products was found by mixing their prepared solution with citicoline sodium (CTN) and nimodipine (NMP). In addition, no chromatographic interference from any of the excipients was found at the retention time of the examined drug after extraction 
of the active ingredient. Besides, the chromatograms of the pharmaceutical formulation samples were checked for the appearance of any extra peaks. Good resolution and absence of interference was attained. So, the proposed method could be successfully applied for the routine analysis of the studied drugs in their dosage forms without any preliminary separation step. Results for determination of these drugs by the proposed method in their dosage forms along with standard addition technique were displayed in Table II.

\section{Limit of detection and limit of quantification}

Limit of detection (LOD) which represent the concentration of the analyte at S/N ratio of 3 and limit of quantitation (LOQ) representing the concentration of analyte at $\mathrm{S} / \mathrm{N}$ ratio of 10 was determined experimentally for the proposed method and results were given in Table II.

Table II. Assay and method validation parameters obtained by applying the proposed RP-HPLC method for simultaneous determination of nimodipine and citicoline sodium in bulk and capsule

\begin{tabular}{lcc}
\hline Analytical term & CTN & NMP \\
\hline Retention time & $2.51 \mathrm{~min}$ & $6.40 \mathrm{~min}$ \\
Wavelength of detection & $270 \mathrm{~nm}$ & $235 \mathrm{~nm}$
\end{tabular}

\begin{tabular}{|c|c|c|}
\hline Linearity & & \\
\hline Range of linearity & $15-400 \mu \mathrm{g} \mathrm{mL}^{-1}$ & $4.5-120 \mu \mathrm{g} \mathrm{mL}^{-1}$ \\
\hline Regression equation & $y=18.9246 x+27.3065$ & $y=70.6529 x+17.1658$ \\
\hline Correlation coefficient (R) & 0.9999 & 0.9995 \\
\hline $\mathrm{LOD}^{*}\left(\mu \mathrm{g} \mathrm{mL}^{-1}\right)$ & 3.487 & 0.487 \\
\hline $\mathrm{LOQ}^{*}\left(\mu \mathrm{g} \mathrm{mL}^{-1}\right)$ & 10.567 & 1.477 \\
\hline $\mathrm{S}_{\mathrm{b}}{ }^{*}$ & 0.080 & 0.824 \\
\hline $\mathrm{S}_{\mathrm{a}}^{*}$ & 19.373 & 54.638 \\
\hline Confidence limit of the slope & $18.9246 \pm 0.222$ & $70.6529 \pm 2.287$ \\
\hline $\begin{array}{l}\text { Confidence limit of the } \\
\text { intercept }\end{array}$ & $27.3065 \pm 53.779$ & $17.1658 \pm 151.675$ \\
\hline $\begin{array}{l}\text { Standard error of the } \\
\text { estimation }\end{array}$ & 25.771 & 74.567 \\
\hline \multicolumn{3}{|l|}{ Precision } \\
\hline Intra day (RSD* \%) & $0.135-0.175$ & $0.079-0.102$ \\
\hline Inter day (RSD* \%) & $0.432-0.614$ & $0.447-0.887$ \\
\hline Drug in dosage form & $100.224 \pm 0.916$ & $99.994 \pm 1.177$ \\
\hline \multicolumn{3}{|l|}{ Accuracy } \\
\hline Drug in laboratory mix. & $100.405 \pm 1.149$ & $99.383 \pm 0.898$ \\
\hline Drug added & $100.158 \pm 1.147$ & $100.812 \pm 1.027$ \\
\hline
\end{tabular}




\section{Robustness}

Robustness is a measure of the method ability to remain unaffected by small variations in the method conditions and is an indication of the method reliability. Robustness was performed by changes in flow rate (changed from $1.0 \mathrm{~mL} \mathrm{~min}^{-1}$ to $0.8 \mathrm{~mL} \mathrm{~min}^{-1}$ and $1.2 \mathrm{~mL} \mathrm{~min}^{-1}$ ), organic strength of mobile phase (acetonitrile percentage changed from $70 \%$ to $68 \%$ and $72 \%$ ), molarity of prepared buffer solution (changed from 20 $\mathrm{mM}$ to $18 \mathrm{mM}$ and $22 \mathrm{mM}$ ) and $\mathrm{pH}$ of the buffered solution of mobile phase (changed from $\mathrm{pH} 3.0$ to $\mathrm{pH} 2.8$ and $\mathrm{pH}$ 3.2). The most important parameter to be studied was the resolution factor between the two peaks of citicoline sodium (CTN) and nimodipine (NMP). It was found that no significant change in resolution factor between citicoline sodium (CTN) and nimodipine (NMP) peaks indicating good robustness of the proposed method. Results were given in Table III.

Table III. Robustness of the proposed HPLC method

\begin{tabular}{|c|c|c|c|c|c|c|c|c|}
\hline \multirow[t]{2}{*}{ Parameter } & \multicolumn{2}{|c|}{$\begin{array}{l}\text { Flow rate } \\
\left(\mathrm{mL} \mathrm{min}^{-1}\right)\end{array}$} & \multicolumn{2}{|c|}{$\mathrm{pH}$} & \multicolumn{2}{|c|}{$\begin{array}{c}\text { Organic } \\
\text { composition (\%) }\end{array}$} & \multicolumn{2}{|c|}{$\begin{array}{l}\text { Buffer solution } \\
\text { molarity (mM) }\end{array}$} \\
\hline & 0.8 & 1.2 & 2.8 & 3.2 & 68 & 72 & 18 & 22 \\
\hline $\begin{array}{l}\text { CTN/NMP-DP } \\
\text { Resolution (acid } \\
\text { hydrolysis) }\end{array}$ & 18.21 & 17.67 & 18.02 & 17.89 & 18.11 & 17.78 & 17.88 & 18.03 \\
\hline $\begin{array}{l}\text { NMP-DP/NMP } \\
\text { Resolution (acid } \\
\text { hydrolysis) }\end{array}$ & 11.83 & 11.64 & 11.79 & 11.68 & 11.82 & 11.59 & 11.69 & 11.78 \\
\hline $\begin{array}{l}\text { CTN/NMP-DP1 } \\
\text { Resolution (basic } \\
\text { hydrolysis) }\end{array}$ & 8.44 & 8.32 & 8.39 & 8.35 & 8.45 & 8.32 & 8.34 & 8.40 \\
\hline $\begin{array}{l}\text { NMP-DP1/NMP-DP2 } \\
\text { Resolution (basic } \\
\text { hydrolysis) }\end{array}$ & 4.65 & 4.59 & 4.64 & 4.60 & 4.67 & 4.59 & 4.60 & 4.64 \\
\hline $\begin{array}{l}\text { NMP-DP2/NMP } \\
\text { Resolution (basic } \\
\text { hydrolysis) }\end{array}$ & 14.24 & 13.99 & 14.23 & 14.18 & 14.31 & 14.17 & 14.16 & 14.24 \\
\hline
\end{tabular}

\section{Statistical analysis of the results}

A statistical analysis of the results obtained by the proposed method and the reference methods for each analyte was carried out by "SPSS statistical package version 11". The difference between groups was tested by ( $t$-test) and ( $F$-value) at $p=0.05$. The test ascertained that there was no significant difference among the methods. Results were given in Table IV.

Table IV. Statistical analysis of the results obtained by the proposed RP-HPLC and the reference methods

\begin{tabular}{lcccc}
\hline & \multicolumn{2}{c}{ CTN } & \multicolumn{2}{c}{ NMP } \\
\cline { 2 - 5 } Statistical Term & HPLC method & $\begin{array}{c}\text { Reference } \\
\text { method }^{* *}\end{array}$ & HPLC method & $\begin{array}{c}\text { Reference } \\
\text { method }^{* * *}\end{array}$ \\
\hline Mean & 100.405 & 100.035 & 99.383 & 99.757 \\
SD & 1.149 & 0.938 & 0.898 & 0.873 \\
RSD & 1.144 & 0.938 & 0.903 & 0.875 \\
\hline $\mathbf{n}$ & 6 & 6 & 6 & 6 \\
\hline
\end{tabular}


Table IV. Statistical analysis of the results obtained by the proposed RP-HPLC and the reference methods (Cont.)

\begin{tabular}{lcccc} 
& \multicolumn{2}{c}{ CTN } & \multicolumn{2}{c}{ NMP } \\
\cline { 2 - 5 } Statistical Term & HPLC method & $\begin{array}{l}\text { Reference } \\
\text { method }^{* *}\end{array}$ & HPLC method & $\begin{array}{l}\text { Reference } \\
\text { method }^{* * *}\end{array}$ \\
\hline Variance & 1.320 & 0.880 & 0.806 & 0.762 \\
$t$-value & & $0.611(2.228)^{*}$ & $0.730(2.228)^{*}$ \\
F-value & $0.373(4.965)^{*}$ & $0.533(4.965)^{*}$ \\
\hline
\end{tabular}

${ }^{*}$ Values in parentheses are the corresponding theoretical $t$-and F-values at $\mathrm{P}=0.05$.

** Reference method for citicoline sodium using HPLC company method.

*** Reference method for nimodipine using HPLC of USP pharmacopeia.

\section{Method Development Discussion}

The development of a simultaneous and sufficiently selective analytical method to determine citicoline sodium (CTN) and nimodipine (NMP) in presence of nimodipine (NMP) acidic and alkaline degradation products, with quantitation sensitivity for the cited two drugs in their binary mixture, was of interest and no analytical method was reported to analyze this mixture simultaneously. I aimed using C18 column which has greater separation ability than C8 columns especially for complex compounds due to chemical nature of packing. Various mobile phase compositions like methanol with water or acetonitrile with water, in different proportions, were attempted in an isocratic mode using Eurosper II C18 column $(250 \mathrm{~mm} \times 4.6 \mathrm{~mm}, 5$ $\mu \mathrm{m}$ ) but optimized separation of all contents was not obtained. Starting use of a buffer solution of $0.02 \mathrm{M}$ $\mathrm{KH}_{2} \mathrm{PO}_{4}$ mixed with different proportions of acetonitrile, an improvement in peak shapes and resolutions was noticed. That was expected as buffer solution has the benefit to resist $\mathrm{pH}$ change upon the addition of acidic or basic compounds, so maintaining the $\mathrm{pH}$ of the solution relatively stable. Using low proportions of acetonitrile gave delayed elution for nimodipine (NMP), because it is strongly attracted to the column particles. But compounds whose polarity is near to that of the mobile phase will be preferentially attracted to it and move faster. Using too high proportions of acetonitrile (more than $82 \%$ ), salting out of buffer solution was observed due to poor solubility of buffers in organic solvents. Triethylamine was added to buffer solution of mobile phase $(0.2 \%, v / v)$ to minimize broadening and tailing of nimodipine (NMP) peak. So best resolutions and peak shapes with reasonable retention times for citicoline sodium (CTN), nimodipine (NMP), and nimodipine (NMP) acid and alkaline degradation products were attained using acetonitrile: $0.02 \mathrm{M} \mathrm{KH}_{2} \mathrm{PO}_{4}$ (containing $0.2 \% \mathrm{v} / \mathrm{v}$, triethylamine and adjusted to $\mathrm{pH} 3.0$ with orthophosphoric acid) $(70: 30, v / v)$, Table I. Flow rate was adjusted to $1 \mathrm{~mL} \mathrm{~min}^{-1}$. Analysis was achieved at ambient temperature $\left(25^{\circ} \mathrm{C}\right)$ on a Eurospher II C18 $(250 \mathrm{~mm} \times 4.6 \mathrm{~mm}, 5 \mu \mathrm{m})$. UV detector was operated at $270 \mathrm{~nm}$ for citicoline sodium (CTN) and at $235 \mathrm{~nm}$ for nimodipine (NMP) and its acidic and alkaline degradation products, where best sensitivity was attained at these selected wavelengths for each compound.

\section{Acid hydrolysis of Nimodipine}

Acid degradation of nimodipine was carried out in $5 \mathrm{M}$ methanolic $\mathrm{HCl}$ as mentioned under Section (4.3). Complete degradation was confirmed using TLC plates and its structure was then elucidated by different spectroscopic techniques. Structure elucidation was confirmed using FTIR spectroscopy, ${ }^{1} \mathrm{H}-\mathrm{NMR}$ as well as LC-MS/MS spectrometry and supposed to be: 2,6-dimethyl-4-(3-nitrophenyl)-1,4-dihydropyridine-3,5dicarboxylic methyl ester (Figure 1c).

The spectroscopic data of the intact drug showed a peak at $3550 \mathrm{~cm}^{-1}$ in the IR spectrum corresponding to $-\mathrm{NH}$ of pyridine ring and a peak at $1500 \mathrm{~cm}^{-1}$ corresponding to carbonyl group, presence of septet peak corresponding to $-\mathrm{CH}$ of isopropyl group at $4 \mathrm{ppm}$, presence of triplet peak corresponding to $\mathrm{CH}_{2}$ of methoxy ethyl moiety at $3.9 \mathrm{ppm}$ and absence of carboxylic protons at $11-13 \mathrm{ppm}$ in ${ }^{1} \mathrm{H}-\mathrm{NMR}$ and the molecular weight of the intact drug at $418.47 \mathrm{~m} / \mathrm{z}$ using LC/MS-MS. Although, the IR spectrum 
of nimodipine acid degradation product showed no significant difference from parent drug, its ${ }^{1} \mathrm{H}-\mathrm{NMR}$ spectrum showed disappearance of both septet peak of $-\mathrm{CH}$ of isopropyl group and triplet peak of $-\mathrm{CH}_{2}$ of methoxy ethyl moiety, and presence of singlet peaks at $3.6 \mathrm{ppm}$ but carboxylic protons still absent. LCMS/MS confirmed the hydrolysis of two ester groups of nimodipine to its corresponding carboxylic acids followed by their esterification to methyl esters via methanol in solution (Fischer-Speier Esterification) as showing the molecular weight of the obtained acid degradation product at $346.33 \mathrm{~m} / \mathrm{z}$ in the negative ion mode. The suggested scheme for nimodipine (NMP) acid degradation is illustrated in Figure 4.

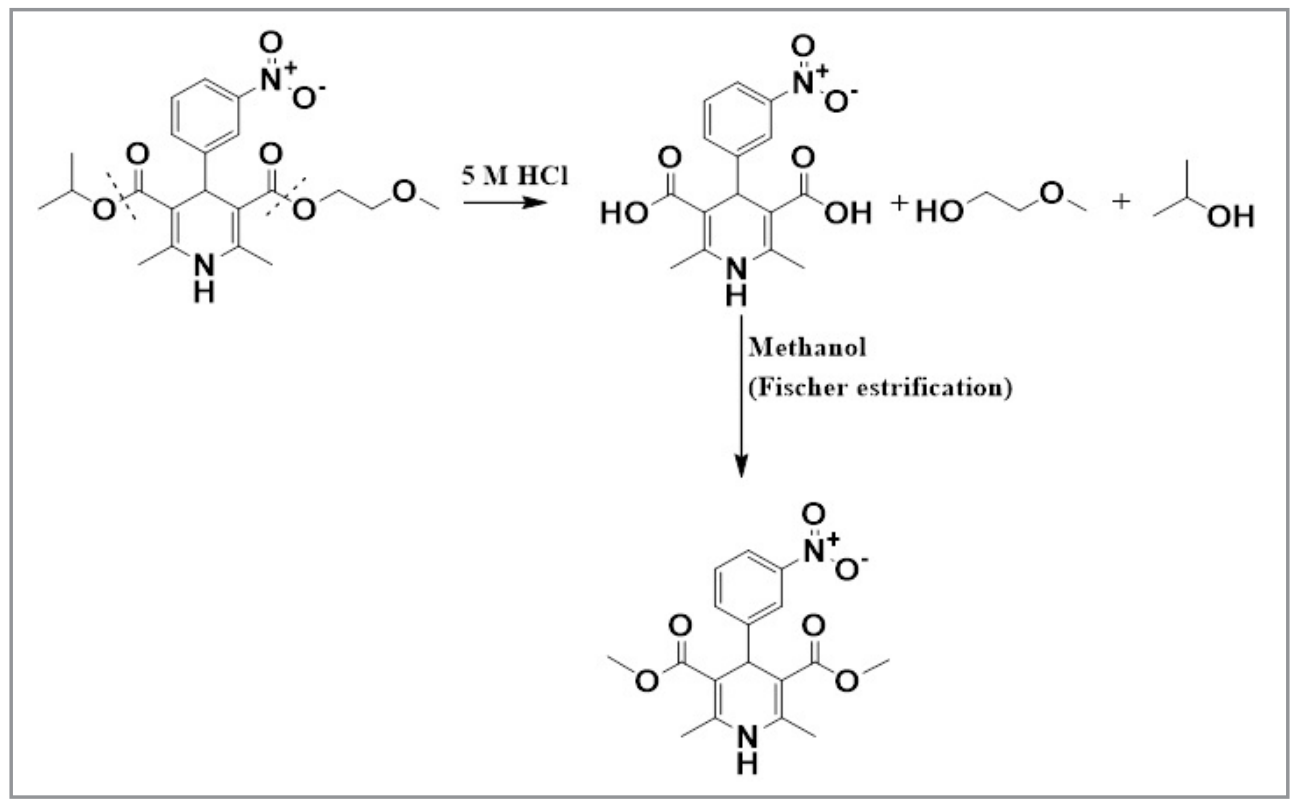

Figure 4. The suggested scheme for nimodipine acid degradation.

\section{Alkaline hydrolysis of Nimodipine}

Alkaline degradation of nimodipine was carried out using $0.25 \mathrm{M} \mathrm{NaOH}$ as mentioned under Section (4.4). Complete degradation was confirmed using TLC plates and its structure was then elucidated by different spectroscopic techniques. Structure elucidation was confirmed using FTIR spectroscopy and LC/MS-MS spectrometry techniques. Two alkaline degradation products were supposed to be formed and they were: 2,6-dimethyl-4-(3-nitrophenyl)-1,4-dihydropyridine-3,5-dicarboxylic acid (Figure 1d) and 5-propan-2-yl 2,6-dimethyl-4-(3-nitrophenyl)-1,4-dihydropyridine-3,5-dicarboxylate (Figure 1e).

Spectroscopic data of intact drug mentioned was utilized. The IR spectrum of nimodipine alkaline degradation products showed appearance of a broad and strong peak at $3630 \mathrm{~cm}^{-1}$ corresponding to $\mathrm{OH}$ group. Peak of $-\mathrm{NH}$ group was shifted to $3100 \mathrm{~cm}^{-1}$. LC-MS/MS confirmed the hydrolysis of one or two ester groups of nimodipine to its corresponding carboxylic acids as showing the molecular weight of the obtained alkaline degradation products at $360.42 \mathrm{~m} / \mathrm{z}$ and $318.28 \mathrm{~m} / \mathrm{z}$ in the negative ion mode. The suggested scheme for nimodipine (NMP) alkaline degradation is illustrated in Figure 5. 


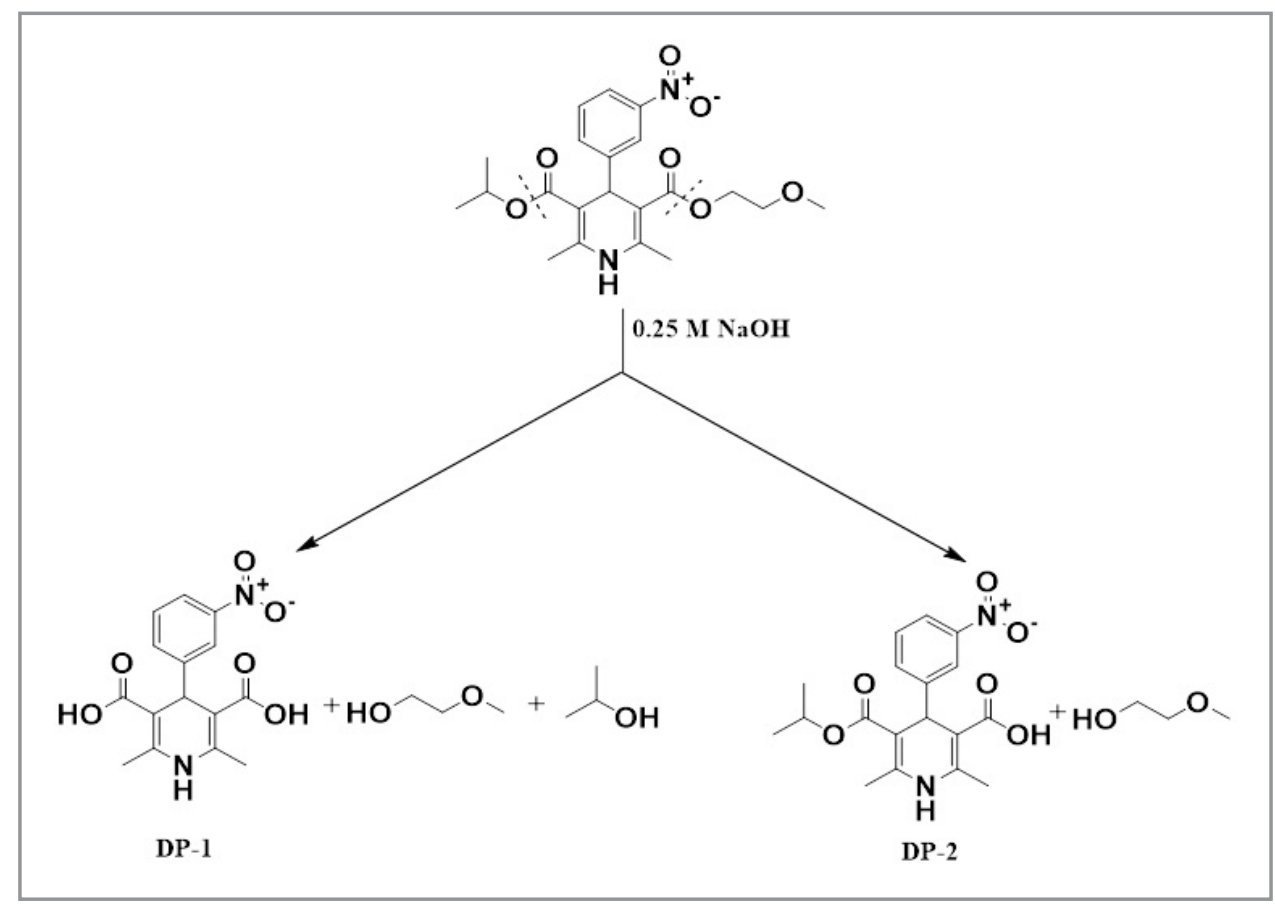

Figure 5. The suggested scheme for nimodipine alkaline degradation.

\section{CONCLUSION}

The proposed RP-HPLC provides simple, accurate and reproducible quantitative analysis for the simultaneous determination of citicoline sodium (CTN) and nimodipine (NMP) in bulk and tablets in presence of nimodipine (NMP) acidic and alkaline drastic forced degradation products. This method was validated as per $\mathrm{ICH}$ guidelines. The proposed method is suitable for the purity assessment of nimodipine (NMP) alone or in combination with citicoline sodium (CTN) in analytical laboratories.

\section{Acknowledgment}

The author thanks National Organization for Drug Control and Research (NODCAR), Giza, Egypt, for carrying out this work.

\section{Conflict of interest}

Nothing to declare.

\section{REFERENCES}

1. The United States Pharmacopeia USP 38, The National Formulary NF 33, by authority of the United States Pharmacopeial Convention, Inc. Maryland, USA, 2015.

2. Langley, M. S.; Sorkin, E. M. Drugs, 1989, 37, pp 669-699 (https://link.springer.com/ article/10.2165\%2F00003495-198937050-00004).

3. Keyrouz, S.; Diringer M. Crit. Care, 2007, 11, Article number 220 (https://doi.org/10.1186/cc5958).

4. Sweetman S. C. Martindale: The Complete Drug Reference, $38^{\text {th }}$ edition. Pharmaceutical Press, London, UK, 2014.

5. O'Neil, M. J. The Merck Index an Encyclopedia of Chemical, Drugs and Biologicals, $14^{\text {th }}$ ed., MERCK and Co. Inc., USA, 2006.

6. Giménez, R.; Raïch, J.; Aguilar, J. Br. J. Pharmacol., 1991, 104, pp 575-578 (http://dx.doi. org/10.1111/j.1476-5381.1991.tb12471.x).

7. Teather, L. A.; Wurtman, R. J. Learn. Mem., 2005, 12, pp 39-43 (http://dx.doi.org/10.1101/lm.83905). 
8. Secades, J. J.; Lorenzo, J. L. Methods Find. Exp. Clin. Pharmacol., 2006, 28, pp 1-56 (https://www. ncbi.nlm.nih.gov/pubmed/17171187).

9. Sobrado, M.; López, M.; Carceller, F.; ,García, A.; Roda, J. Neuroscience, 2003, 118 (1), pp 107-113 (https://doi.org/10.1016/S0306-4522(02)00912-0).

10. Krishnaiah, Y. S. R.; Bhaskar, P.; Jayaram, B.; Rao, P. M. M. Asian J. Chem., 2003, 15, pp 1302-1306 (http://www.asianjournalofchemistry.co.in/user/journal/viewarticle.aspx?ArticlelD=15_3_11).

11. Shang, X.; Ma, S.; Li, Z. J. Chem, 2013, 2013 (http://dx.doi.org/10.1155/2013/612082).

12. Zhao, Y.; Zhai, D.; Chen, X.; Yu, Q.; He, H.; Sun, Y.; Gao, Z.; Wang, L.; Wang, H.; Han, D.; et al. J. Chromatogr. Sci., 2010, 48, pp 81-85 (http://dx.doi.org/10.1093/chromsci/48.2.81).

13. Nascimento, D. F.; Moraes, M. O.; Bezerra, F. A. F.; Pontes, A. V.; Uchoa, C. R. A.; Moraes, R. A.; Leite, I. O.; Santana, G. S.; Santana, A. P. M.; Leite, A. L. A.; et al. Braz. J. Pharm. Sci., 2010, 46, pp 665-677 (http://dx.doi.org/10.1590/S1984-82502010000400008).

14. Dan-Bo, Y.; Jia-Bi, Z.; Rui-Qin, L.; Zhi-Qiang, H.; Jin-Qiu, S. Anal. Lett., 2008, 41, pp 533-542 (http:// dx.doi.org/10.1080/00032710801912441).

15. Kasture, V. S.; Pawar, S. S.; Patil, P. P.; Musmade, D. S.; Ajage, R. K.; Ganjendra, G. Int. J. Pharm., 2014, 4 (2), pp 189-195 (Available at: http://citeseerx.ist.psu.edu/viewdoc/ download?doi=10.1.1.684.4227\&rep=rep1\&type=pdf).

16. Riekes, M. K.; Rauber, G. S.; Kuminek, G.; Tagliari, M. P.; Cardoso, S. G.; Stulzer, H. K. J. Chromatogr. Sci., 2013, 51 (6), pp 511-516 (http://dx.doi.org/10.1093/chromsci/bms174).

17. Mohamed, S.; Riva, R.; Contin, M. J. Chromatogr. B Analyt. Technol. Biomed. Life Sci., 2016, 1028, pp 94-99 (http://dx.doi.org/10.1016/j.jchromb.2016.06.012).

18. Maradiya, H. K.; Pansara, V. H. Indian J. Pharm. Sci., 2013, 75 (2), pp 238-241 (Available at: https:// pubmed.ncbi.nlm.nih.gov/24019577/).

19. Sandhya, S. M.; Jyothisree, G.; Babu, G. Int. J. Pharma Res. \& Rev., 2014, 3, pp 20-25 (https:// www.semanticscholar.org/paper/Development-of-a-Validated-RP-HPLC-Method-for-the-SandhyaJyothisree/b8f7134069b5c72e481db58c48625a174cfe1479?p2df)

20. Surani, S.; Kabra, P.; Kimbahune, R.; Sunil, K.; Nargund, L. V. G. Int. J. PharmTech. Res., 2012, 4 (3), pp 1136-1141 (http://sphinxsai.com/2012/july_sept12/Pharm/pdfpharm/PT=32(1136-1141)\%20 JS\%2012.pdf).

21. Bindaiya, S.; Sahu, K.; Patel, K. S.; Trivedi, P. Lat. Am. J. Pharm., 2011, 30 (4), pp 794-798 (http:// www.latamjpharm.org/resumenes/30/4/LAJOP_30_4_2_4.pdf).

22. Chen, K.; Liu, X.; Wei, C.; Yuan, G.; Zhang, R.; Li, R.; Wang, B.; Guo, R. J. Bioequiv. Availab., 2011, 3 (4), pp 72-76 (http://dx.doi.org/10.4172/jbb.1000062).

23. Panda, S. S.; Kumar, B. V.; Mohanta, G.; Panda, J. Int. J. Pharm. Sci. Nanotech., 2013, 6, pp 19521957 (https://doi.org/10.37285/ijpsn.2013.6.1.5).

24. Patel, J. A.; Panigrahi, B.; Patel, C. N.; Ramalingan, B. Chron. Young Sci., 2011, 2 (3), pp 150-154 (https://ddtjournal.net/?view-pdf=1\&embedded=true\&article=a047dc6654cf206f4d02a3b3f32aa949S axemw\%3D\%3D).

25. ICH Harmonized Tripartite Guideline. Validation of Analytical Procedures: Text and Methodology Q2(R1), International Conference on Harmonization 2005, 2013. 


\section{SUPPLEMENTARY MATERIAL}

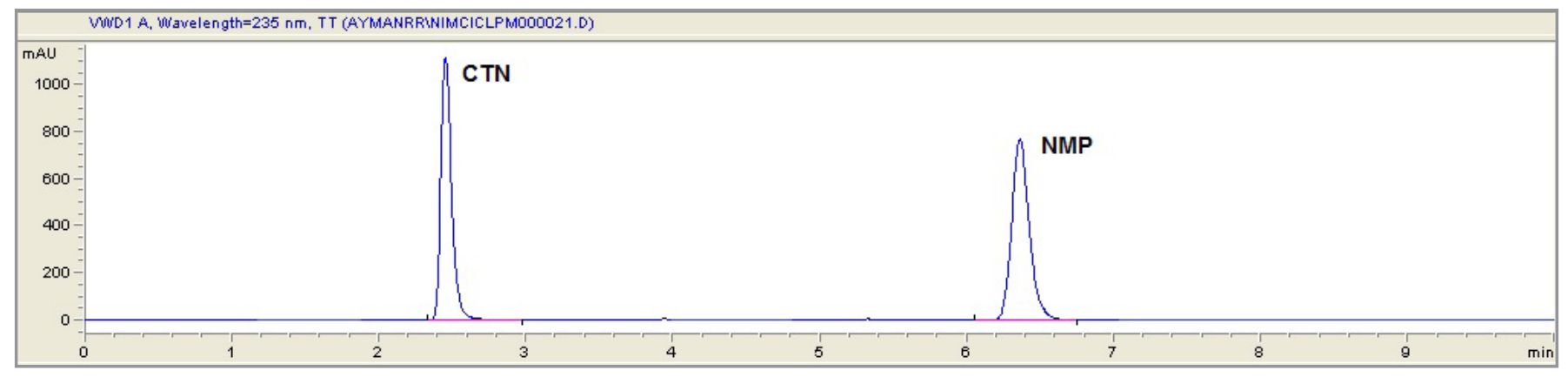

A typical HPLC chromatogram of Nimodilat plus $®$ sample solution $\left(305 \mu \mathrm{gmL}^{-1} \mathrm{CTN}\right.$ and $\left.91.5 \mu \mathrm{gmL}^{-1} \mathrm{NMP}\right)$

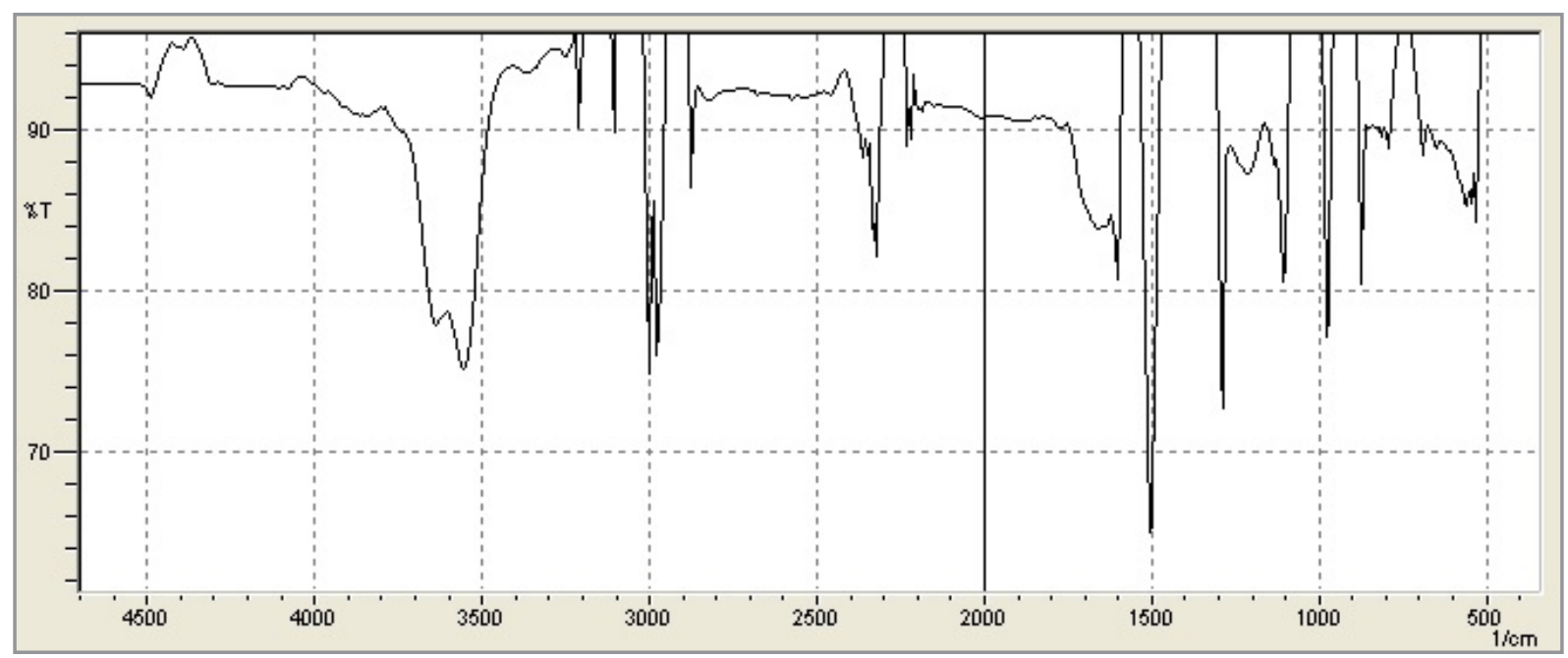

FTIR spectrum of nimodipine

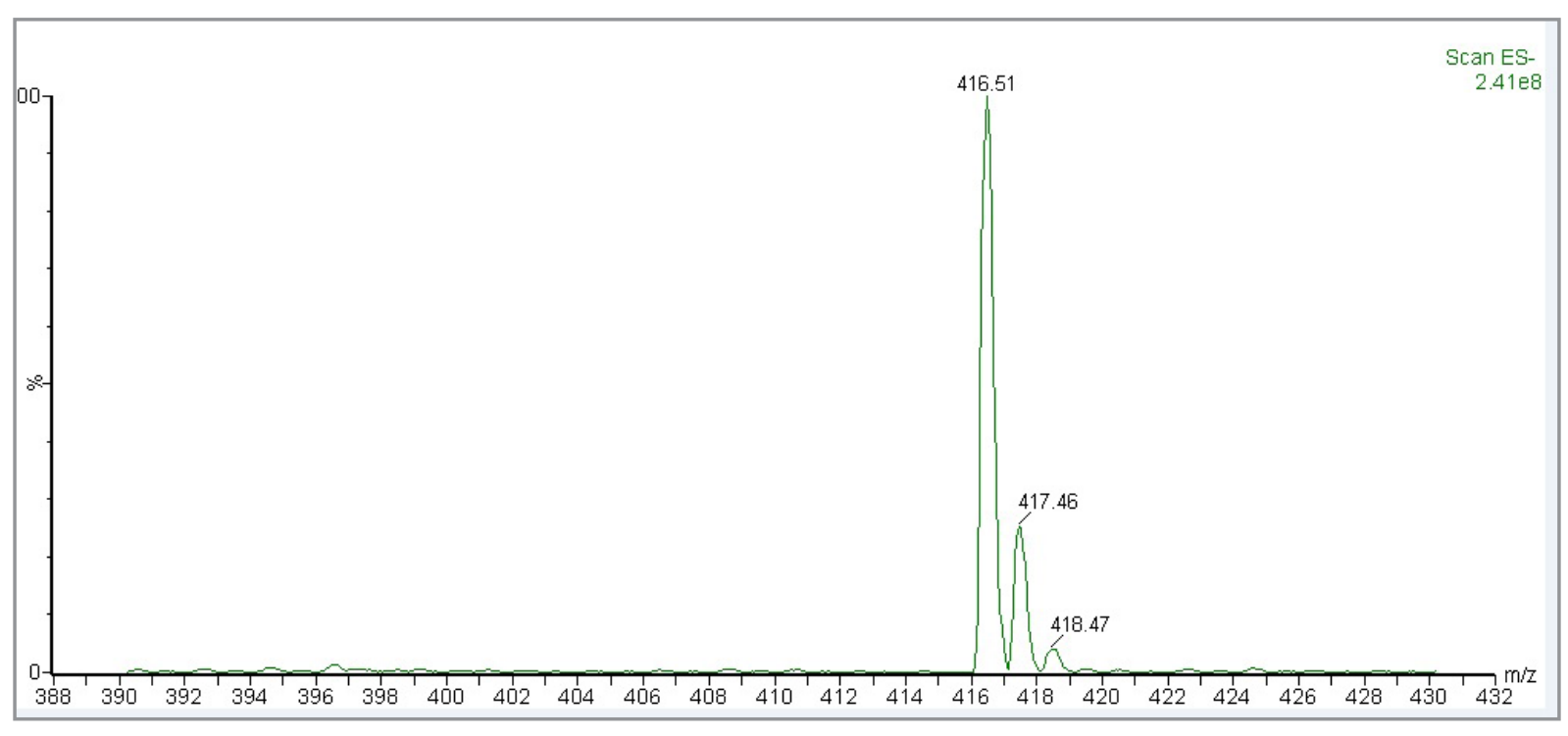

LC-MS/MS spectrometry of nimodipine 


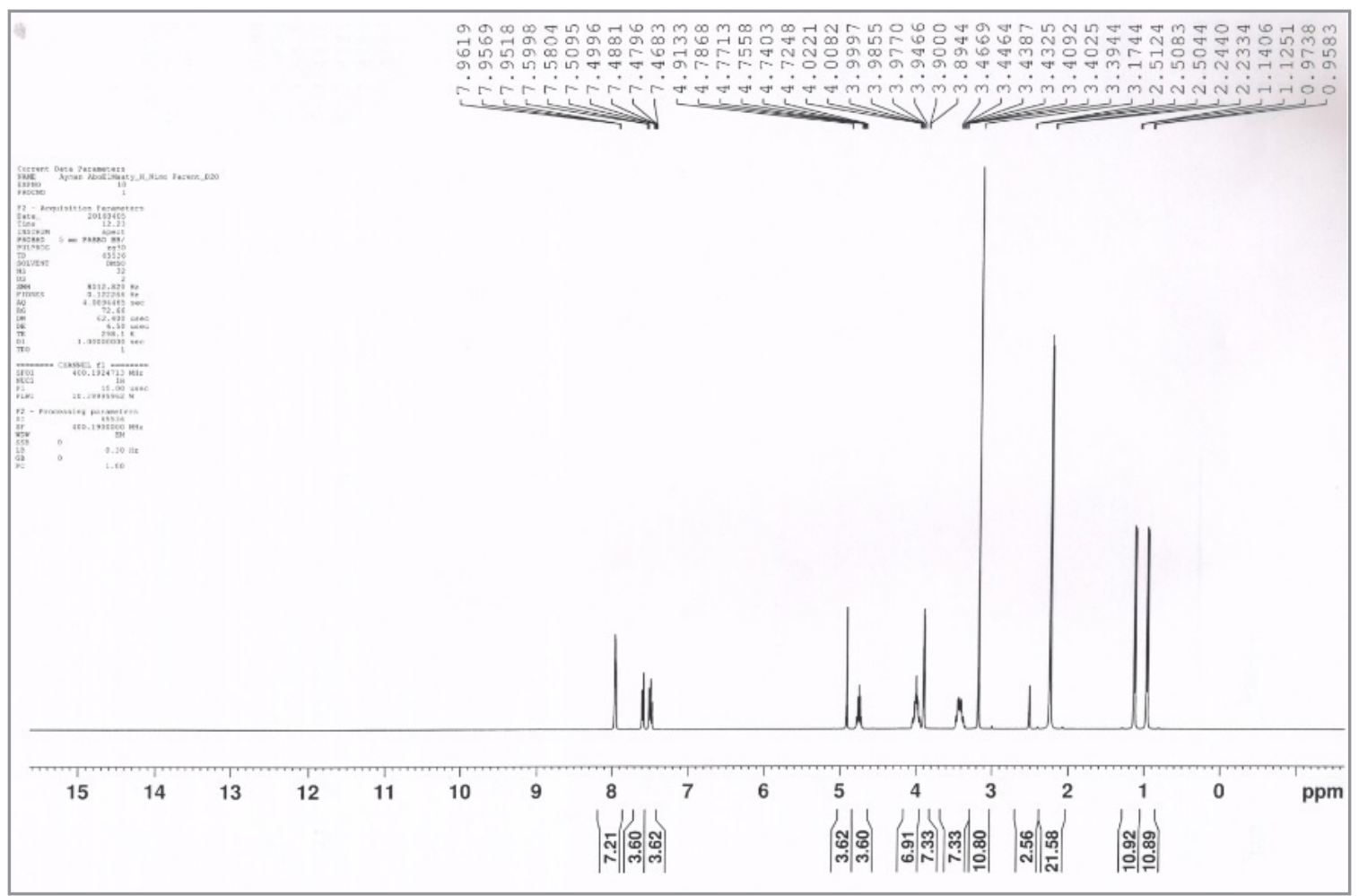

${ }^{1} \mathrm{H}-\mathrm{NMR}$ spectrum of nimodipine using deuterium oxide

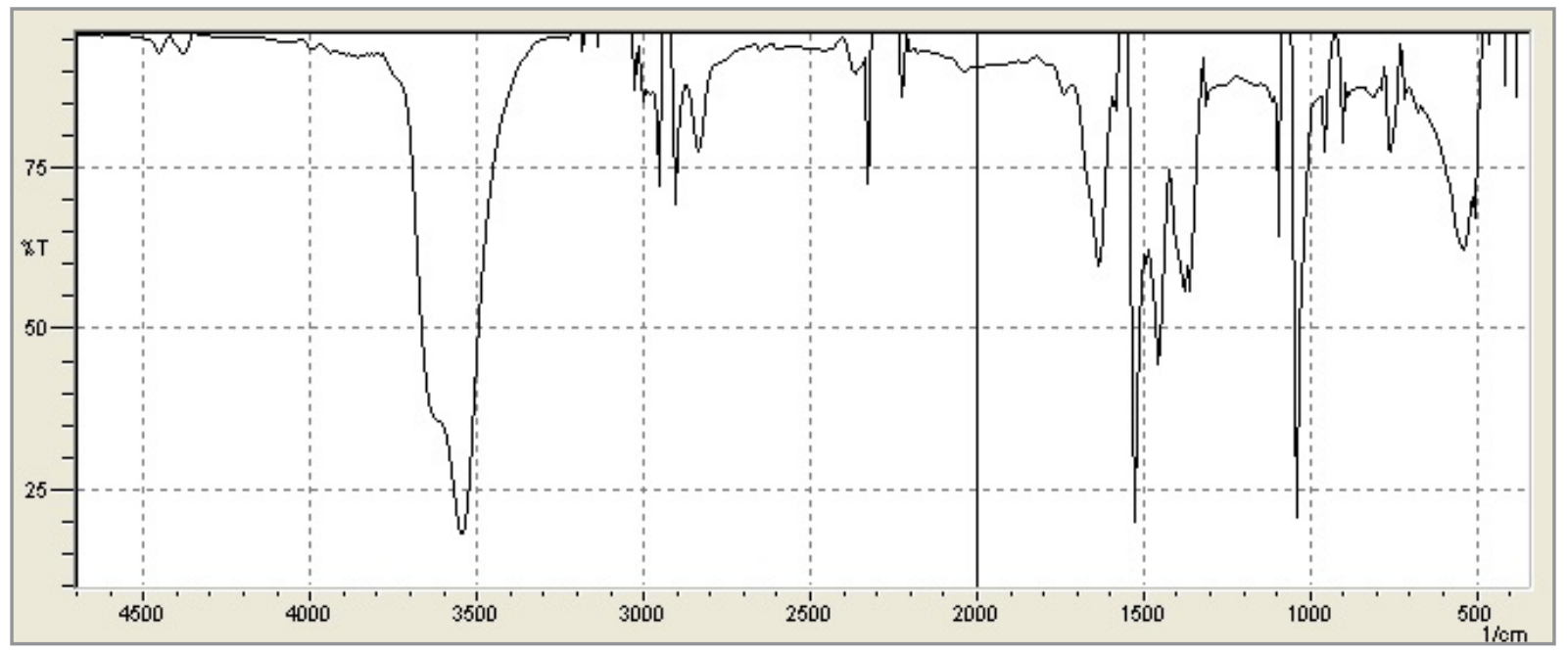

FT-IR spectrum of nimodipine acid forced degradation product 


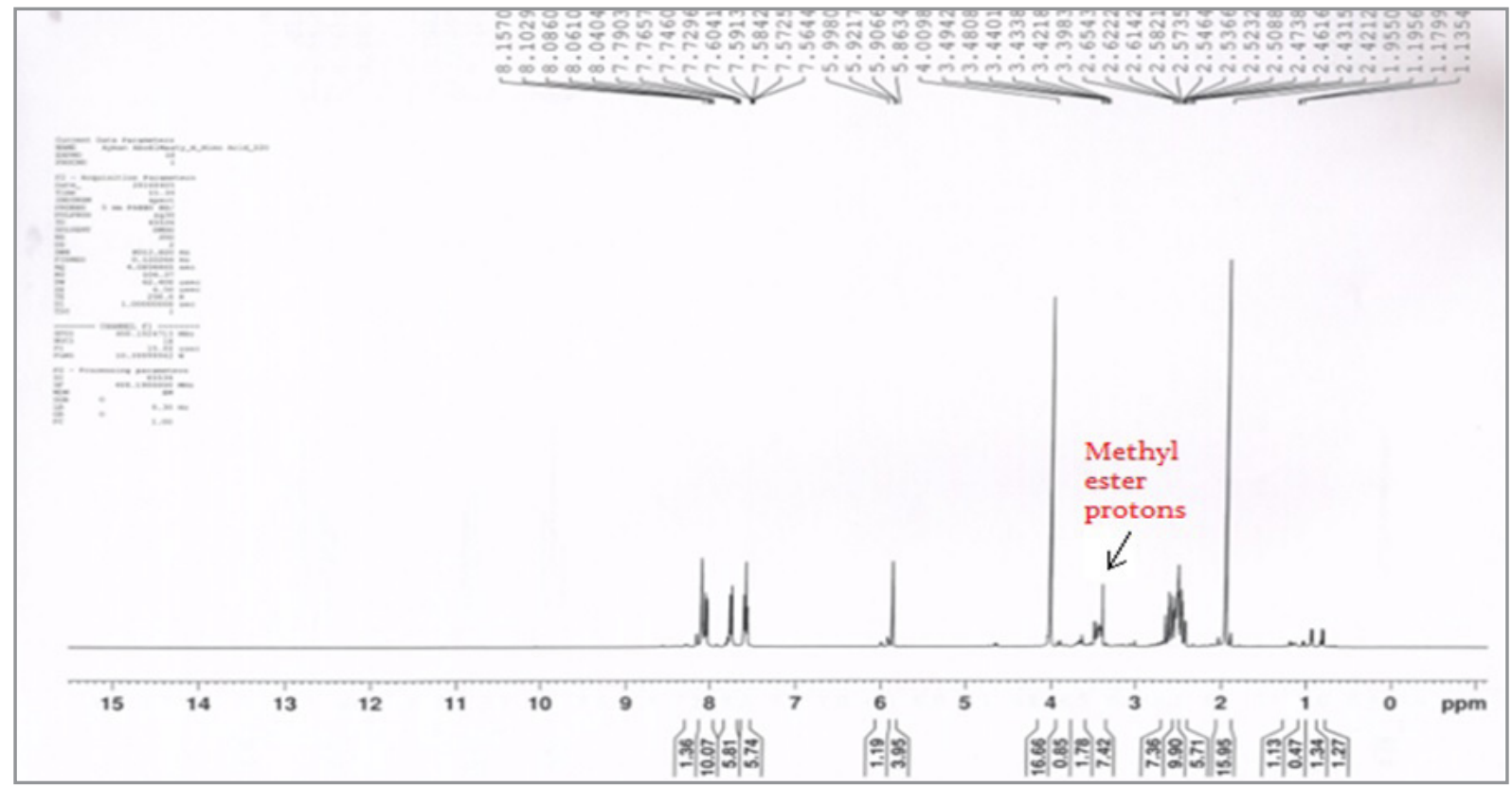

${ }^{1} \mathrm{H}-\mathrm{NMR}$ spectrum of nimodipine acid degradation product using deuterium oxide

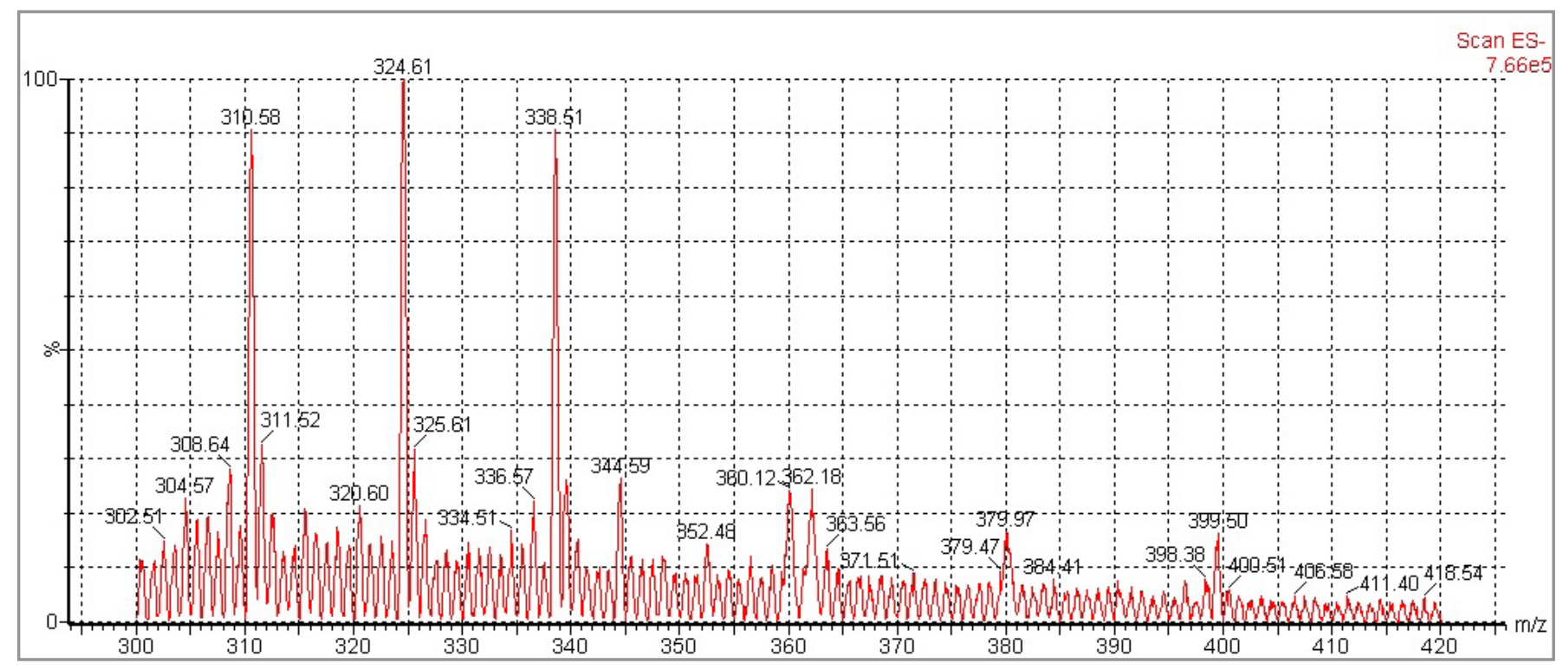

LC-MS/MS spectrometry of nimodipine acid forced degradation product 


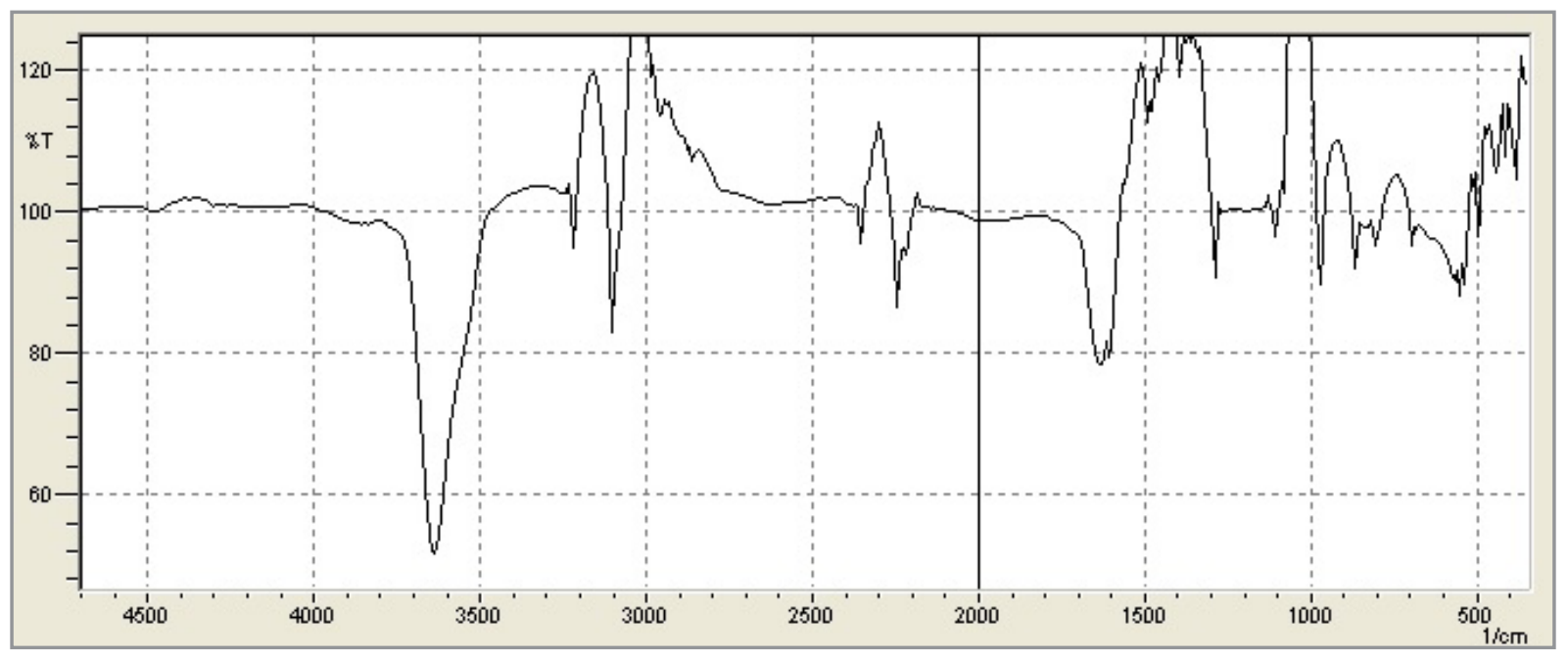

FT-IR spectrum of nimodipine alkaline forced degradation products

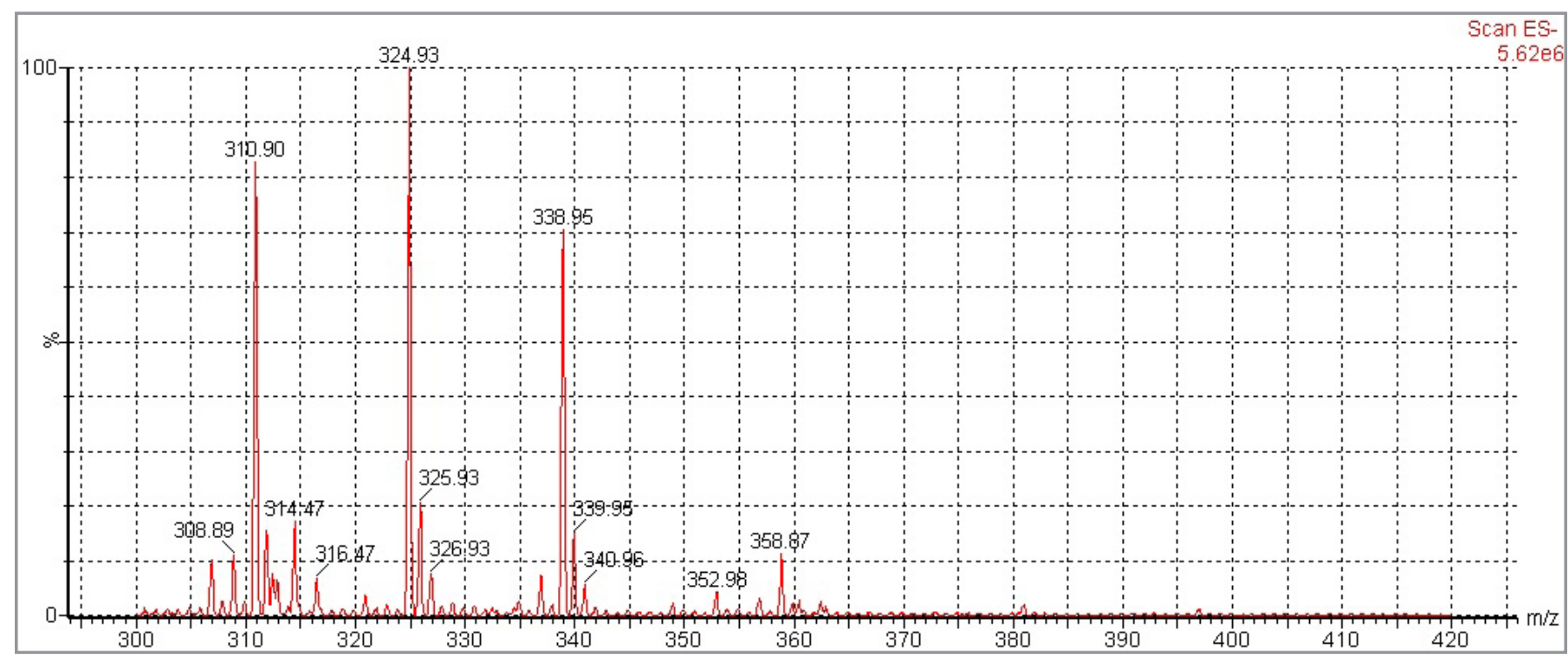

LC-MS/MS spectrometry of nimodipine alkaline forced degradation products 